\title{
In-Situ Nanoscopic Visualization of Stress Corrosion Cracking of High-Strength Aluminum Alloy by Scanning Atomic Force Microscopy
}

\author{
K. Komai, K. Minoshima and T. Miyawaki* \\ Department of Mechanical Engineering, Kyoto University, Kyoto 606-01, Japan \\ * Asahi Glass, Funahashi 273, Japan
}

\begin{abstract}
An atomic force microscope (AFM) equipped with a small three-point bending testing machine was applied to perform in situ visualization of intergranular stress corrosion (SC) crack growth under a constant displacement. The tests were conducted on a high-strength 7075-T6 aluminum alloy in laboratory air. The AFM was capable of imaging surface topography of growing SC crack in the order of nanometer. The AFM has extremely high spatial resolution, and it was capable of monitoring very slowly growing SC crack. Even when it grew at the order of $0.1 \mathrm{~nm} / \mathrm{s}$, it grew continuously at the order of microns. When the crack grew along the grain boundary inclined to tensile stress direction, not only Modes I and II crack tip displacement, but also Mode III displacement was observed. However, Mode I stress intensity derived from crack tip displacement was responsible for its crack growth. The tip of a growing SC crack in laboratory air was very sharp. However, when the environment was changed to vacuum, the crack tip became blunt, and the crack retarded. When the environment was rechanged to laboratory air, the crack restarted after some crack retardation time, and the tip became sharp again. We discuss the SC crack growth mechanisms based upon nanoscopic in situ visualization by using AFM.
\end{abstract}

\section{INTRODUCTION}

Most damage issues in machines and structures are caused by environmentally induced material degradation in an operating environment, including corrosion fatigue and stress corrosion cracking. In order to clarify the fracture and damage mechanisms of environmentally induced material degradation, serial highmagnification observation of damage initiation and growth processes are necessary. The traditional methods employed for such purposes are scanning electron microscopy [1] and measurements of microscopic distributions of corrosion current density, for example, by a scanning vibratory electrode technique [2,3]. In the former case, the tests are periodically interrupted and the sample surface is examined in a completely different environment of vacuum from the test environment, and therefore, the in situ or serial observation of changes in surface damage is impossible. Besides, the vertical resolution is insufficient for investigating the very early initiation stage of environmentally induced cracking and corrosion damage. In the latter case, the available information is limited to electrochemical reactions.

As contrast with these, scanning tunneling microscopy (STM), that was first developed in 1982 [4], is revolutionizing the study of surface physics, electrochemical researches, corrosion [5], and quantitative fractography [6,7]. It is capable of imaging nanoscopic topography of surfaces not only in vacuum but also in air or in aqueous solutions. Although STM imaging of nonconducting surfaces is impossible, atomic force microscopy (AFM), that was developed in 1986 [8], is capable of imaging topography of nonconducting surface. Up to now, these microscopes are called scanning probe microscopes.

The authors et al. $[9,10]$ have reported that STM and AFM are capable of performing nanoscopic in situ observation of corrosion damage, including stress corrosion cracking (SCC), and have discussed advantage and disadvantage between them for nanoscopic observation of corrosion damage. The conclusions are: AFM is more suitable compared with STM, from the standpoints of scanning speed, stability of operations in solutions, capability of imaging non-conducting surfaces, and so on. 
In this investigation, the authors conducted nanoscopic, in situ observation of growing stress corrosion (SC) crack of a high-strength aluminum alloy in laboratory air by using AFM. Special attention was paid for quantitative evaluation of crack shapes, and the effects of environment change of laboratory air and vacuum were investigated, and the fracture mechanisms of SCC are discussed.

\section{EXPERIMENTAL PROCEDURES}

The material tested was a high-strength $\mathrm{Al}-\mathrm{Zn}-\mathrm{Mg}$ alloy, 7075 [11]. The chemical composition and heat treatments are listed in Tables 1 and 2 . The $0.2 \%$ offset yield strength and tensile strength are respectively $410 \mathrm{MPa}$ and $460 \mathrm{MPa}$. Shape and dimensions of test specimens are shown in Figure 1. The specimen thickness was $1 \mathrm{~mm}$. The sample surface was carefully polished with \#2000 emery paper, followed by $1 \mu \mathrm{m}$ diamond paste and $0.04 \mu \mathrm{m}$ silica powder, which gave satisfactory flat sample surface for observing in the order of nanometer.

An atomic force microscope (AFM) was used to perform in situ, nanoscopic observation of SC crack growth. The AFM unit operating in air and/or solutions was connected to the control station, both of which were manufactured by Seiko Instrument Industries (Japan). The unit was on an isolator, and the station controlled the operation of the unit and the necessary image processing of the AFM images. In order to perform in situ visualization of a growing, part-through SC crack, the three-point bending jig shown in Figure 1 was used. The applied stress was evaluated by curvature of a specimen, which was measured by using a scanning, three-dimensional mapping system based upon astigmatic focus error signal method using laser [12]. The SCC tests were conducted in laboratory air (temperature: $15-20^{\circ} \mathrm{C}, \mathrm{RH}: 55-60 \%$ ). In order to investigate the influence of vacuum conditioning on SC crack growth, a sample that had a growing SC crack was conditioned in vacuum of $1 \times 10^{-3} \mathrm{~Pa}$ for three to eight days, and the SC crack behavior before and after vacuum conditioning was examined by the AFM.

\section{EXPERIMENTAL RESULTS AND DISCUSSIONS 3.1 Fracture Surface Morphology}

Figure 2 shows fracture surface obtained in SCC tests conducted in air, imaged with AFM. The surface was dominated by intergranular cracking, which was the same as $\mathrm{SCC}$ in a $3.5 \% \mathrm{NaCl}$ solution [11]. When we observe the intergranular cracking by using an scanning electron microscope, the surface looked very smooth. However, when the surface was imaged with the AFM with atomic resolution, extremely small nodules with dimensions of about $15 \mathrm{~nm}$ could be seen.

\subsection{Stable SC Crack Growth Behavior in Laboratory Air}

Figure 3 shows in situ visualization of a growing, part-through SC crack in laboratory air of 7075 aluminum alloy: the brightness of each position expresses the height, and the brightest point corresponds to the highest, and the darkest one the lowest. A gray scale shows the height difference of the highest and the lowest points, showing, in this case, $0.810 \mu \mathrm{m}$ in maximum height difference. The image was taken after five-day loading, and the crack length amounted about $1 \mathrm{~mm}$. The principal tensile stress acted in the horizontal direction. The crack grew along the grain boundary to the triple grain boundary shown by an arrow, and then it changed the crack growth direction. When we observed the crack tip at a lower mag-

Table 1: Chemical composition of $7075 \mathrm{Al}$ alloy.

\begin{tabular}{ccccccccc}
\hline $\mathrm{Cu}$ & $\mathrm{Fe}$ & $\mathrm{Si}$ & $\mathrm{Mg}$ & $\mathrm{Mn}$ & $\mathrm{Zn}$ & $\mathrm{Cr}$ & $\mathrm{Ti}$ & $\mathrm{Al}$ \\
\hline 0.37 & 0.02 & 0.01 & 2.11 & 0.01 & 6.19 & $<0.001$ & 0.001 & $\mathrm{Bal}$ \\
\hline
\end{tabular}

Table 2: Heat treatments of $7075 \mathrm{Al}$ alloy.

\begin{tabular}{ccc}
\hline Solution Treatments & Quenching & Aging (Oil Bath) \\
\hline $723 \mathrm{~K} 14.4 \mathrm{ks}$ & 273K Water & $363 \mathrm{~K} .3 .6 \mathrm{ks} \rightarrow 433 \mathrm{~K}, 10.8 \mathrm{ks}$ \\
\hline
\end{tabular}

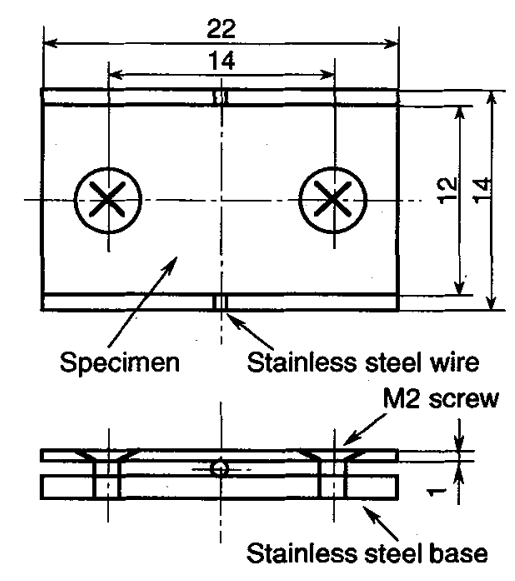

Figure 1: Shape and dimensions of a test specimen and three-point bending testing jig. 


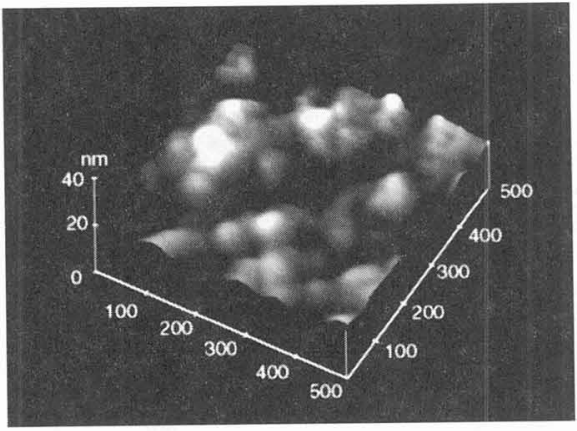

Figure 2: AFM topography of intergranular fracture surface of stress corrosion cracking of $7075 \mathrm{Al}$ alloy. All dimensions are in $\mathrm{nm}$.

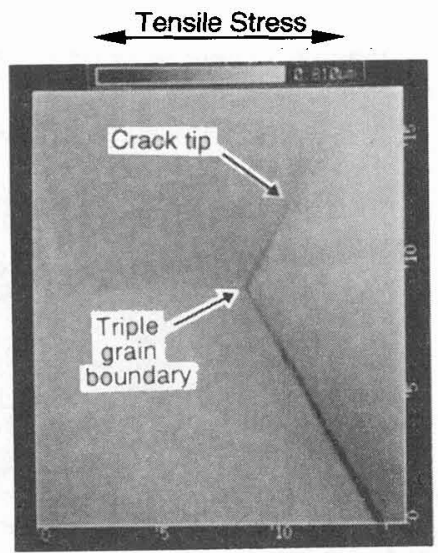

Figure 3: In situ visualization of growing SC crack in laboratory air (Scanning size: $15.9 \times 17.6 \mu \mathrm{m}$, Maximum roughness: $810 \mathrm{~nm}$ ).

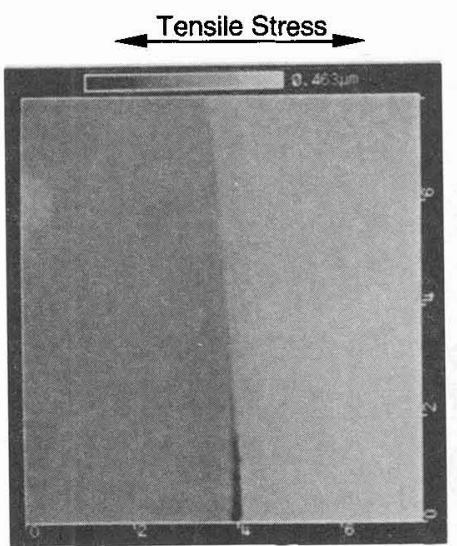

(a) Low-magnification AFM image (Scanning size: $7.6 \times 8.1 \mu \mathrm{m}$, Maximum roughness: $463 \mathrm{~nm}$ )

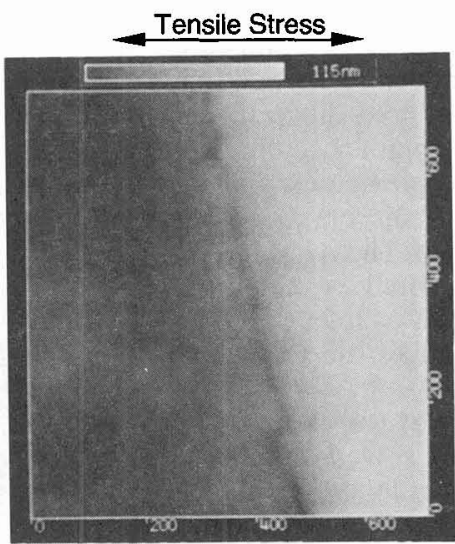

(b) High-magnification AFM image (Scanning size: $716 \times 773 \mathrm{~nm}$, Maximum roughness: $115 \mathrm{~nm}$ )

Figure 4: In situ visualization of growing SC crack in laboratory air

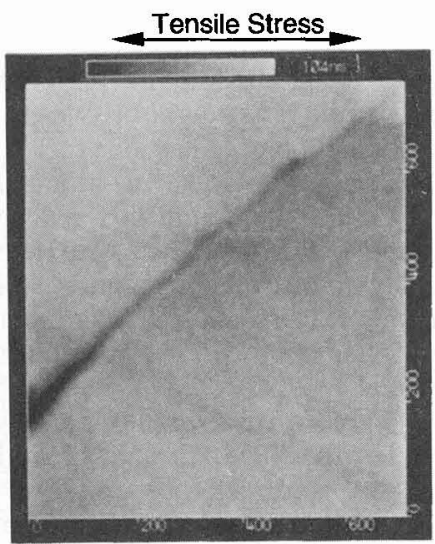

Figure 5: In situ high-magnification visualization of growing SC crack in laboratory air (Scanning size: $716 \times 773 \mathrm{~nm}$, Maximum roughness: $104 \mathrm{~nm}$ ).

nification (see Figure 4(a)), the crack path looked straight. However, at higher magnification (Figure 4(b)), the crack grew with zig-zag path of an order of about $100 \mathrm{~nm}$, which was larger than the nodules observed in fracture surface (about $15 \mathrm{~nm}$ : see Figure 2).

Figure 5 shows the AFM image of the same crack shown in Figures 3 and 4, although the image was after one month loading. The high-magnification AFM image (Figure 5) shows that crack path looked rather straight: compare Figure 4(b) and Figure 5. The zig-zag crack path or fluctuation was about $20 \mathrm{~nm}$, which was in the same order of the nodules observed in the intergranular fracture surface. These mean that: although at lower magnification as Figure 4(a), intergranular SC crack path looked straight, the nanoscopic crack path was different, depending on testing condition and crack length. In the case of Figure 4, preconditioned time in laboratory air was shorter than the case shown in Figure 5, resulting in lower hydrogen content in the material. Therefore, the intergranular SC (HE) crack grew with some amounts of transgranular cracks.

Figure 6 shows the AFM imaging of a growing SC intergranular crack (crack length: about $5 \mathrm{~mm}$ ) in laboratory air, whose crack path was about $70^{\circ}$ against the direction of principal tensile stress. The image shows that there was a height difference between two adjacent grains by the crack, and this indicates that the crack grew not only under mode I loading, but also under modes II and III loading. This result is consistent with the results obtained in 7N01 aluminum alloy, which was reported elsewhere [10]. Cross sections of A- 


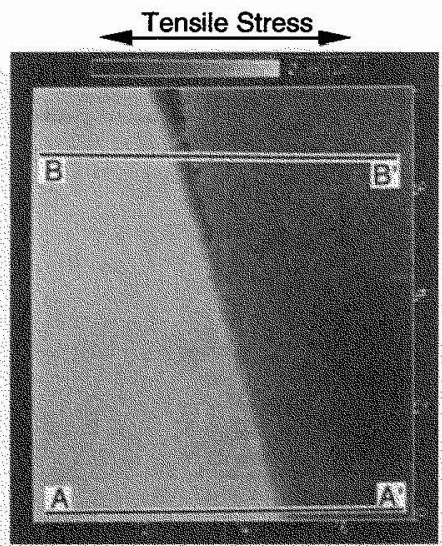

Figure 6: In situ visualization of inclined growing SC crack (Scanning size: $7.6 \times 8.1 \mu \mathrm{m}$, Maximum roughness: $661 \mathrm{~nm}$ )

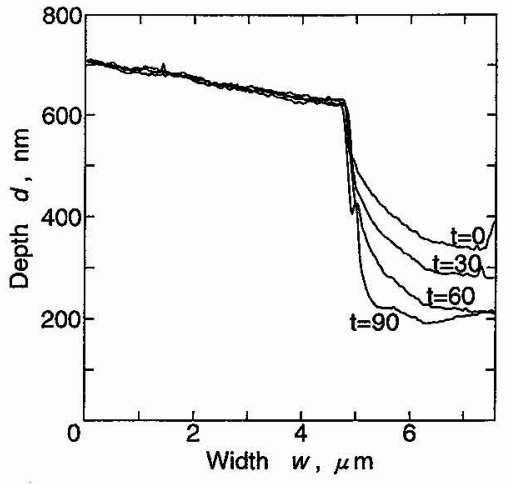

Figure 7: Changes in cross section along A-A' line in Figure 6. (Unit in time: $\mathrm{min}$ )
A' and B-B' lines in Figure 6, which corresponded to preand post-crack opening section, are respectively shown in Figures 7 and 8 . Along the pre-crack opening section line, the difference of height of two grains, i.e., mode III displacement, increased as the crack tip approached the A-A' line (Figure 7). However, along the post-crack opening section line, the height difference of adjacent grains decreased (Figure 8) with crack extension. The AFM has extremely high vertical resolution, and thereby, in situ imaging and measurement of changes in section lines or out-ofplane displacement are possible, unlike the traditional methods.

Figure 9 shows the loci of an SC crack tip determined by the AFM. The crack length observed was about 1 $\mathrm{mm}$, and the direction of principal tensile stress parallels the $\mathrm{x}$-axis (abscissa). Figure 10 shows the relationship between time and crack length, which was measured along the crack path. From the figure, the average crack growth rate could be obtained at about $6.0 \times 10^{-10} \mathrm{~m} / \mathrm{s}(=0.6 \mathrm{~nm} / \mathrm{s})$ : we must note that the crack grew steadily in the order of $\mu \mathrm{m}$, without any crack retardation or crack acceleration. Other advantage of AFM can be deduced

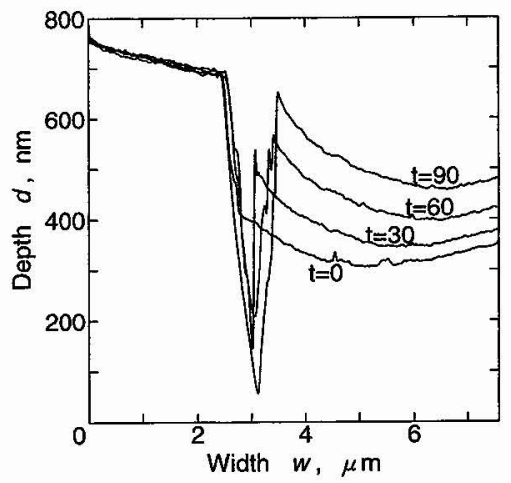

Figure 8: Changes in cross section along B-B' line in Figure 6. (Unit in time: $\mathrm{min}$ )

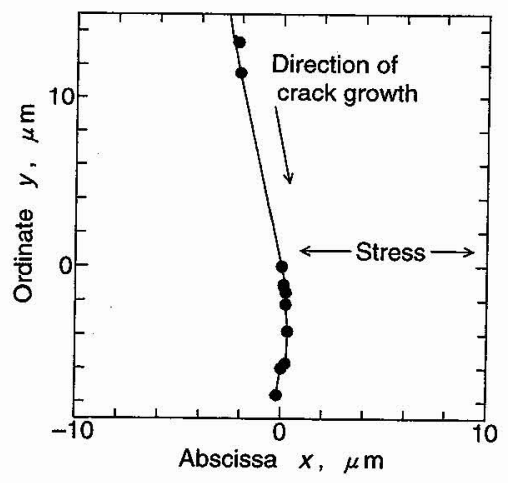

Figure 9: Loci of SC crack in laboratory air. 


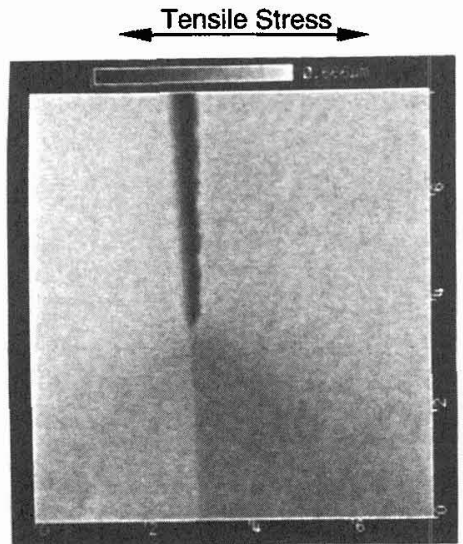

(a) 20 minutes after eight-day vacuum conditioning (Scanning size: $7.6 \times 8.1 \mu \mathrm{m}$, Maximum roughness: $666 \mathrm{~nm}$ ).

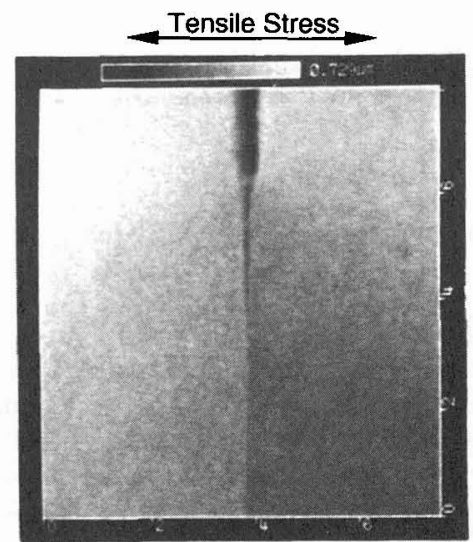

(b) 240 minutes after eight-day vacuum conditioning (Scanning size: $7.6 \times 8.1 \mu \mathrm{m}$, Maximum roughness: $729 \mathrm{~nm}$ ).

Figure 11: In situ visualization of SC crack, which had been conditioned in vacuum.

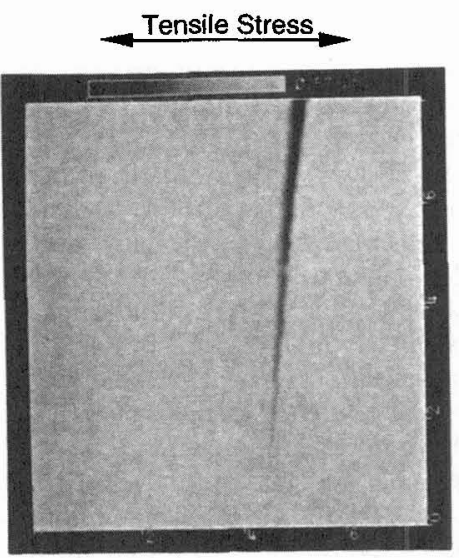

(a) Before vacuum conditioning (Scanning size: $7.6 \times 8.1 \mu \mathrm{m}$, Maximum roughness: $578 \mathrm{~nm}$ ).

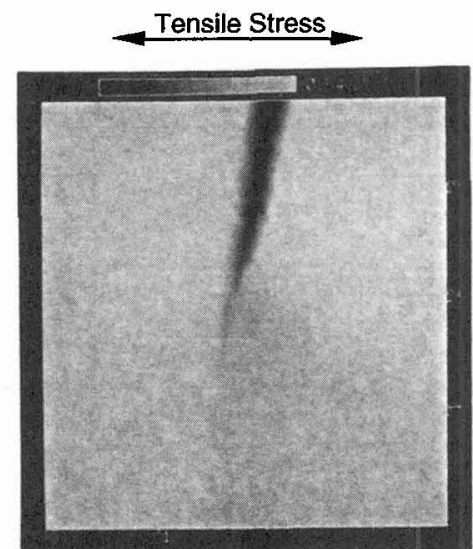

(c) 120 minutes after seven-day vacuum conditioning (Scanning size: $3.7 \times 3.9 \mu \mathrm{m}$, Maximum roughness: $548 \mathrm{~nm}$ ).

Figure 12: In situ visualization of SC crack growth before and after vacuum conditioning.

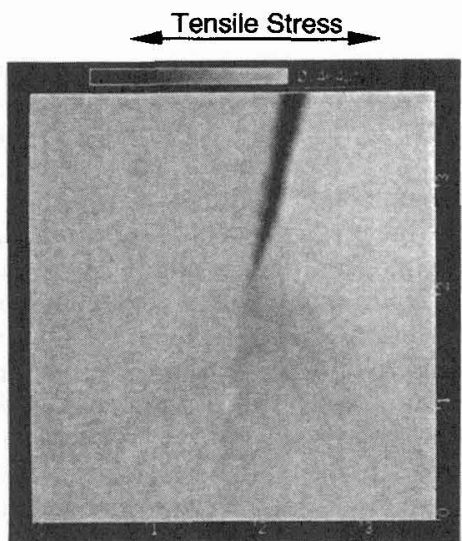

(b) 36 minutes after seven-day vacuum conditioning (Scanning size: $3.7 \times 3.9 \mu \mathrm{m}$, Maximum roughness: $464 \mathrm{~nm}$ ).

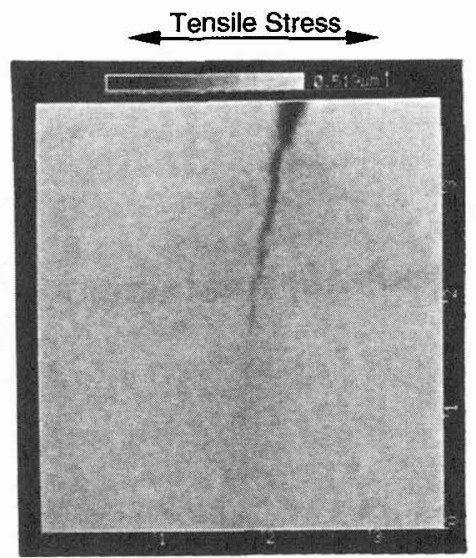

(d) 150 minutes after seven-day vacuum conditioning (Scanning size: $3.7 \times 3.9 \mu \mathrm{m}$, Maximum roughness: $519 \mathrm{~nm}$ ). 
by this figure: comparing with other crack measurement methods such as optical microscopy, AFM has extremely higher vertical and horizontal resolution, and thereby extremely low crack growth rate can be measured by making such a short-time test, as well as crack growth rate fluctuation, if any.

\subsection{Environment-Change Effects on SC Crack Growth}

Figure 11 shows AFM images of an SC crack in air, whose crack had been conditioned in vacuum for eight days: the SC crack had grown in laboratory air, perpendicular to the principal tensile stress, and then the environment was changed from air to vacuum. The sample was conditioned in vacuum for eight days, and the environment was again re-changed to air, and the SC crack growth was observed in air by using AFM. Figure 12 shows AFM imaging of another SC crack, before and after seven-day vacuum conditioning. The crack grew, in this case, in the direction inclined by $80^{\circ}$ against the principal tensile stress. The AFM imaging was done for both cases in laboratory air.

After vacuum conditioning, the SC crack retarded for about 140 minutes for the case shown in Figure 11 (see Figure 11(a)), and for 100 minutes for the case shown in Figure 12 (see Figure 12(b)), and then they started to grow again (see Figure. 11(b), and Figures 12(c)-(d)). The crack opening displacement (CTOD) of the crack before vacuum conditioning, was very small, or the crack tip was extremely sharp. However, after vacuum conditioning, the crack tip became blunt, with a larger CTOD value. The SC crack initiated at the blunted crack tip, and it started to grow again.

Figures 13 and 14 respectively show changes in crack opening displacement, CTOD, before and after vacuum conditioning, for the case shown in Figure 12. The CTOD was measured $1 \mu \mathrm{m}$ behind the crack tip. The figures also show changes in crack length. The time adopted in Figure 14 was elapsed time after the environment was re-changed from vacuum to air. Before vacuum conditioning, the SC crack grew steadily without any crack retardation, having an average crack growth rate of $0.32 \mathrm{~nm} / \mathrm{s}$. The associated CTOD value kept also constant at about $175 \mathrm{~nm}$. After seven-day vacuum conditioning, however, the CTOD value became larger, with about $300 \mathrm{~nm}$, and the crack retarded. The CTOD value further became larger just before the crack started again. With elapsed time, the crack grew at the same growth rate as that before vacuum conditioning, and the CTOD value gradually became smaller with crack extension, and finally it settled at $175 \mathrm{~nm}$, which almost equaled to the value before vacuum conditioning. The changes in CTOD value and crack growth behavior of the SC crack shown in Figure 11 was similar.

As was discussed before, the CTOD value became larger and the crack retarded, when the sample was conditioned in vacuum. This is because hydrogen in the material was discharged in vacuum, and the hydrogen content became smaller for SC crack to grow, resulting in crack retardation. The increased CTOD resulted from creep deformation at crack tip, which was promoted by a decrease in hydrogen content in the material. When the environment was changed from vacuum to air, hydrogen was again charged through water molecules in air, which caused SC crack growth due to hydrogen embrittlement, and the CTOD became smaller, with the same value as that before vacuum conditioning. The crack retardation time observed after the environment was changed from vacuum to air corresponded to time required for hydrogen adsorption and diffusion to increase hydrogen content in the material to cause SC crack.



Figure 13: Crack length and crack tip opening displacement as a function of time (Before vacuum conditioning)

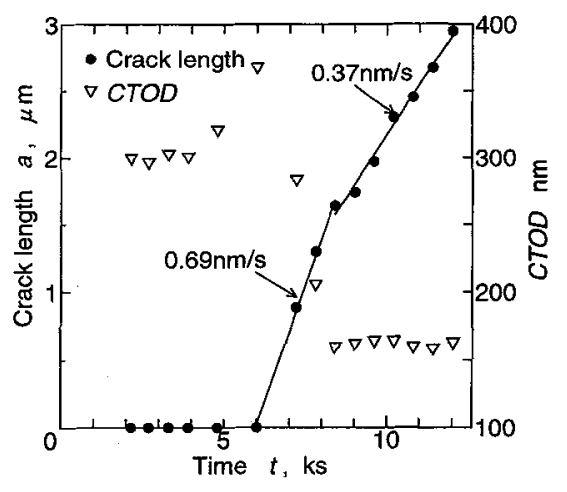

Figure 14: Crack length and crack tip opening displacement as a function of time (after seven-day vacuum conditioning). 


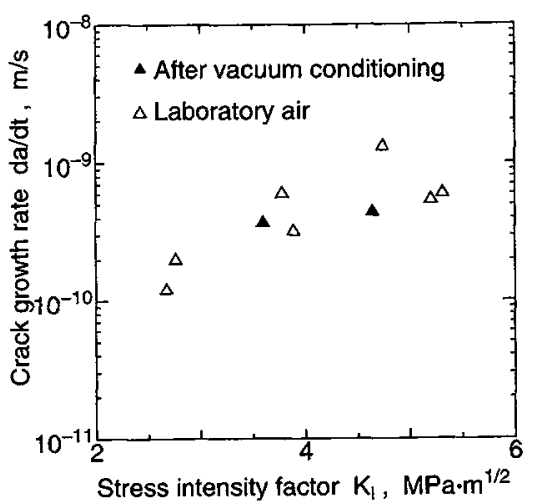

Figure 15: SC crack growth rate as a function of Mode I stress intensity, $\mathrm{K}_{\mathrm{I}}$.

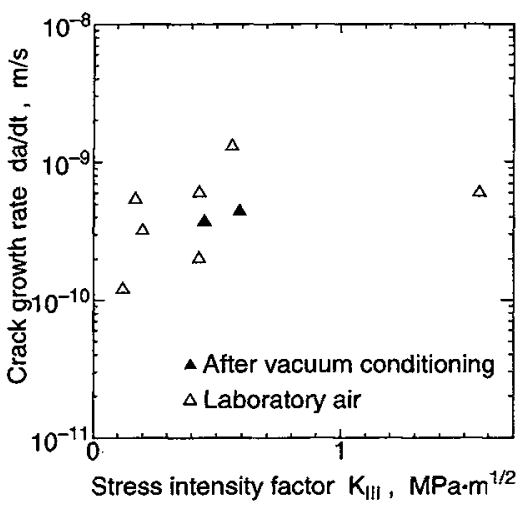

Figure 16: SC crack growth rate as a function of Mode III stress intensity, $\mathbf{K}_{\text {III }}$.

\subsection{SC Crack growth Rate}

The crack growth rates obtained in this investigation were plotted against stress intensity factor. Assuming the crack as an elastic one in a small-scale yielding condition, the stress intensity factor was evaluated by using crack opening displacement: in-plane deformation of a crack was assumed to attribute to mode I deformation, and out-of-plane deformation to mode III deformation, and mode I and mode III stress intensity factors were calculated by using CTOD values behind $500 \mathrm{~nm}$ from the crack tip. The relationships between crack growth rate and mode I and mode III stress intensity factor were respectively plotted in Figures 15 and 16. The growth rates plotted in the figures were obtained only when the crack grew in a steady manner.

The crack growth rates obtained after changing the environment from vacuum to air were plotted by solid marks. The growth rate after the environment change was the same as those obtained in laboratory air, or the growth rates obtained without any environment changes._Moreover, the crack length in figures ranged from $0.9 \mathrm{~mm}$ to $5 \mathrm{~mm}$. However, no crack acceleration due to chemically short crack effects [13], was observed.

When comparing Figure 15 with Figure 16, crack growth rates were determined by mode I stress intensity, with more precise manner: in this material/environment system, hydrogen embrittlement was responsible, and mode I stress intensity determined crack growth rate. The same results were also reported in high-strength steel: the SC crack was dominated by mode I stress intensity, not by mode III intensity.

\section{CONCLUSIONS}

This investigation demonstrates that AFM is capable of performing in situ, nanoscopic and topographic visualization of growing stress corrosion cracks in the order of nanometer. The AFM was applied to in situ observation of a growing stress corrosion crack of a high-strength aluminum alloy, 7075, and attention was paid for quantitative evaluation of crack shapes, and the effects of environment change between laboratory air and vacuum on crack growth. This investigation yielded the following conclusions.

1. AFM is capable of performing in situ, nanoscopic and topographic visualization of growing SC crack, and extremely low crack growth rate can be evaluated even by performing a short-time test, or extremely short crack extension. This will show scatter or fluctuation of crack growth rate, if it exists.

2. AFM has extremely high vertical resolution, and thereby in situ imaging and measurements of changes in section line or out-of-plane displacement are possible.

3. SC crack grows in a steady manner, even though the crack growth rate is extremely low as the order of $10^{-10} \mathrm{~m} / \mathrm{s}(=0.1 \mathrm{~nm} / \mathrm{s})$.

4. When a sample is conditioned in vacuum, the crack tip becomes blunt and then it retards. When the environment was re-changed from vacuum to air, the crack tip again becomes sharp, and it grows again. In vacuum, hydrogen in the material is discharged, and therefore, the SC crack retards, because the hydrogen content was too low for stress corrosion crack growth.

5. Mode I stress intensity is responsible for stress corrosion crack growth of 7075 aluminum alloy in laboratory air, not mode III stress intensity, although mixed mode deformation of crack, i.e., mode I, 
mode II, and mode III displacements are observed by AFM.

\section{REFERENCES}

[1] Komai, K., Minoshima, K., Kinoshita, S. and Kim, G., JSME Inter'l Journal, 31(1988), 606.

[2] Ishikawa, Y. and Isaacs, H.S., Presented at Conf. Corros. and Exploitation of Aluminum Alloys, Crafield, England, 1983.

[3] Minoshima, K., Ogawa, S. and Komai, K., Proc. 11th Inter'l Corrosion Congress, 5(1990), 5.477.

[4] Binnig, G., Rohrer, H., Gerber, Ch., and Weibel, E., Appl. Phys. Lett., 40(1982), 57.

[5] Masuda, H., Matsuoka, S. and Nagashima, N., Jour. Jpn. Corros. Eng., 40(1991), 754.

[6] Matsuoka, S., Sumiyoshi, H, and Ishikawa, K, Trans. Jpn Soc. Mech. Eng., 56(1990), 2091.

[7] Minoshima, K., Endo, M., Miyawaki, T., and Komai, K., Trans. Jpn Soc. Mech. Eng., 61(1995), 1587.

[8] Binnig, G., Quate, C.F, and Gerber, C., Phys. Rev. Lett., 56(1986), 930.

[9] Komai, K., Minoshima, K., and Itoh, M., Jour. Mater. Sci., Japan, 43(1994), 329.

[10] Komai, K., Minoshima, K., and Itoh, M., Jour. Mater. Sci., Japan, 43(1994), 336.

[11] Endo, K. Komai, K. and Minoshima, K., Materials, Experimentation and Design in Fatigue, Westburry House, (1981), 77.

[12] Komai, K., Minoshima, K., and Ohki, H., Jour. Mater. Test. Res. Assoc. Jpn, 35(1990), 158.

[13] Gangloff, R.P., Metallurg. Trans. 16A(1985), 953.

[14] Hayden, H.W. and Floreen, S., Corrosion-NACE, 27(1971), 429.

[15] John, C. St. and Gerberich, W.W., Mettallurg. Trans., 4(1973), 589. 